Disclosure of Interest: K. Krüger Consultant for: AbbVie, BMS, Celgene, Janssen Biologics, MSD, Pfizer, Roche, and Sanofi-Aventis, G. Burmester Consultant for: AbbVie, BMS, MSD, Pfizer, Roche, and UCB, S. Wassenberg Consultant for: AbbVie, Chugai, Janssen Biologics, MSD, Novartis, Pfizer, Roche, and UCB, M. Bohl-Bühler Consultant for: AbbVie, Hexal, MSD, Roche, and UCB, M. Thomas Employee of: MSD Sharp \& Dohme GmbH Germany

DOI: 10.1136/annrheumdis-2017-eular.5154

\section{FRI0204 COMPARISON THE LONG-TERM CLINICAL OUTCOMES BETWEEN NONTNF-INHIBITORS VERSUS TNF-I IN RA PATIENTS WHO FAILED TO A FIRST TNF-I}

P. Bogas ${ }^{1}$, C. Plasencia ${ }^{1}$, D. Pascual-Salcedo ${ }^{2}$, G. Bonilla ${ }^{1}$, E. Moral ${ }^{1}$, C. Tornero ${ }^{1}$, L. Nuño ${ }^{1}$, A. Villalba ${ }^{1}$, D. Peiteado ${ }^{1}$, A. Martinez ${ }^{2}$, B. Hernandez ${ }^{2}$, A. Balsa ${ }^{1} .{ }^{1}$ Rheumatology; ${ }^{2}$ Immunology, Hospital Universitario la Paz, Madrid, Spain

Background: There are many biological therapies for Rheumatoid Arthritis (RA) with different mechanisms of action and good efficacy rate; however, up to $40 \%$ of patients (pts) fail to respond to the 1st biologic agent, and it is still not clear what strategy to follow after showing inadequate response to tumor necrosis factor $\alpha$ inhibitors (TNF-i)

Objectives: To assess the clinical response and survival (SVV), in our cohort of RA pts that discontinued the 1st TNF-i, of a 2nd TNF-i vs a nonTNF-i, both in the global cohort and in the subpopulation that dropped out the 1st TNF-I due to inefficacy

Methods: This observational study included 110 pts in the RA-Paz cohort who previously suspended Ifx (68\%) or Ada (32\%) between 1999-2016. Two groups were established as they switched to a TNF-i or nonTNF-i. Clinical response was evaluated by DAS28, Delta-DAS28 ( $\triangle \mathrm{DAS} 28$ ) and EULAR response (E-resp). The assessments were performed at $6(\mathrm{v}-6)$ and 12 months $(\mathrm{v}-12)$ since initiating 2nd biological agent and during the last visit prior to drug discontinuation or ending of the study for those who did not interrupt the drug (v-end). Statistical analysis was performed using SPSS version 20.0

Results: Of the 110 pts who had stopped Ifx or Ada as 1 st TNF-i, $65 \%$ changed to a 2 nd TNF-i. The $84 \%$ of the overall pts were women. The mean age was $64 \pm 14$ years and the mean time of 2 nd biologic drug was $3.71 \pm 3.51$ years. $61 \%$ associated methotrexate at the beginning of 2 nd biologic agent and $56 \%$ at the v-end, without differences between those who switched to TNF-i and those who did to nonTNF-i. At $v-6$ and $v-12$, there was no difference in $\triangle$ DAS28 [at $v-6: 1.3 \pm 1.4$ in TNF-i and $1.2 \pm 1.2$ in nonTNF-i $(\mathrm{p}=0.919)$, at $v-12: 1.3 \pm 1.5$ in TNF-I and $1.2 \pm 1.1$ in nonTNF-i $(\mathrm{p}=0.852)]$. In contrast, at $\mathrm{v}$-end, pts with nonTNF-i showed a higher clinical improvement ( $\triangle \mathrm{DAS} 28: 0.68 \pm 1.7$ in TNF-i, $1.8 \pm 1.1$ in nonTNF-i, $\mathrm{p}=0.002$ ). At $\mathrm{v}-6$, the TNF-i group achieved higher good E-resp rate ( $41 \%$ vs $18 \%, p=0.035)$, but there was no difference at $v-12(36 \%$ in TNF-I vs $23 \%$ in nonTNF-i, $p=0.435$ ). However, at v-end, the nonTNF-I group achieved better E-resp (good resp: $38 \%$ in nonTNF-i vs $25 \%$ in TNF-I, no resp $18 \%$ in nonTNF-i vs $50 \%$ in TNF-i, $p=0.01)$. Likewise, $100 \%(n=7)$ of the pts that finished 2nd biologic agent by remission, had changed to a nonTNF-i $(p<0.00001)$. There were no differences regarding 2nd biologic drug SVV (mean SVV time of $5.7 \pm 0.66$ in TNF-I, $4.3 \pm 0.59$ in nonTNF-i, $p=0.797$ ). When analyzing the cohort that discontinued 1st TNF-I because of inefficacy, at $v-6$ and $v-12$ there were no differences between switchers to TNF-I and nonTNF-i in $\triangle \mathrm{DAS} 28$ [v-6: $1.4 \pm 1.4$ vs $0.9 \pm 1 \mathrm{p}=0.164) ; \mathrm{v}-12: 1.5 \pm 1.4$ vs $1 \pm 1, \mathrm{p}=0.192)$ ], but at $\mathrm{v}$-end, the nonTNF-i group reached a higher $\triangle \mathrm{DAS} 28(0.9 \pm 1.5$ in TNF-i, $1.6 \pm 1$ in nonTNF-i, $p=0.031)$

\begin{tabular}{|c|c|}
\hline \multicolumn{2}{|c|}{ Demographic characteristics. } \\
\hline Age (years) & $64 \pm 13,9$ \\
\hline Sex (female) & $92(84 \%)$ \\
\hline Smokers. & $18(16 \%)$ \\
\hline BMI & $26,6 \pm 7,7$ \\
\hline Disease duration (xears) & $16,7 \pm 8,04$ \\
\hline RF + & $94(85 \%)$ \\
\hline Anti-CCP + & $96(89 \%)$ \\
\hline $\begin{array}{l}\text { Duration of treatment 1st } \\
\text { biological (years) }\end{array}$ & $3,2 \pm 3,1$ \\
\hline Basal DMARDs ( $2^{\circ}$ biological) & $99(90 \%)$ \\
\hline Basal MTX $\left(2^{\circ}\right.$ biological $)$ & $67(61 \%)$ \\
\hline v-Final FAMEs $\left(2^{\circ}\right.$ biological $)$ & $93(86 \%)$ \\
\hline v-Final MTX $\left(2^{\circ}\right.$ biological) & $60(56 \%)$ \\
\hline Basal CPR (2॰ biological) & $15,2 \pm 18,7$ \\
\hline Basal ESR $\left(2^{\circ}\right.$ biologicall $)$ & $42 \pm 24,1$ \\
\hline Basal DAS $\left(2^{\circ}\right.$ biological) & $5,55 \pm 1,3$ \\
\hline
\end{tabular}

Conclusions: In our sample of RA patients who suspended Ifx/Ada as 1st TNF-i, switching to a 2nd biologic agent did not show relevant clinical differences between a TNF-i and a nonTNF-i within the 1st year of treatment. However, in the long-term, switching to a nonTNF-i shows enhanced clinical benefits with no impact on survival vis-à-vis a 2nd TNF-i. Despite the efficacy of TNF-i, new therapeutic targets are needed for those who fail to respond to these biological agents

Disclosure of Interest: None declared

DOI: 10.1136/annrheumdis-2017-eular.4383

\section{FRI0205 CORRELATION OF PATIENT PREFERENCES TO TREATMENT OUTCOMES IN PATIENTS WITH RHEUMATOID ARTHRITIS (RA) TREATED WITH ANTI-TNF AGENTS IN GREECE. THE PANORAMA STUDY}

P. Sidiropoulos ${ }^{1}$, A. Bounas ${ }^{2}$, P. Athanassiou ${ }^{3}$, A. Andrianakos ${ }^{4}$, E. Petrikkou ${ }^{5}$, A. Drosos ${ }^{6}$, D. Vassilopoulos ${ }^{7}{ }^{1}$ Department of Rheumatology, Clinical Immunology and Allergy, University of Crete, Heraklion: ${ }^{2}$ Private practice, Patras; ${ }^{3}$ Rheumatology Division, General Hospital of Thessaloniki St. Paul, Thessaloniki; ${ }^{4}$ IASO General Hospital; ${ }^{5}$ Medical Affairs, MSD, Athens; ${ }^{6}$ Rheumatology Clinic, University of loannina, loannina: ${ }^{7}$ Joint Rheumatology Program, Clinical Immunology-Rheumatology Unit, 2nd Department of Medicine and Laboratory, National and Kapodistrian University of Athens, Athens, Greece

Background: Route and frequency of administration of treatment options may be an important differentiator between drugs that are used to treat RA and patient preferences may influence adherence to and outcomes of therapy.

Objectives: The objective of this study was to assess the correlation between the fulfillment of patient preferences and clinical and patient reported outcomes. Methods: PANORAMA was a non-interventional, prospective, multicenter, cohort study. Patients were either biologic naïve or experienced who initiated/switched to anti-TNF at enrollment. Post physician's anti-TNF choice, patients completed a preferences questionnaire over attributes related to anti-TNF treatment. Satisfaction with treatment was assessed with the TSQM questionnaire and compliance (proportion of full doses/planned) was recorded via the use of a patient diary. Persistence was defined as the time period between first and last anti-TNF administration. The observational period was 12 months, with study visits every 3 months.

Results: A total of 254 patients were enrolled in the study. The mean patient age was $58.3 \pm 13.4$ years, $82.7 \%$ were female, $65.4 \%$ were biologic naïve and $66.1 \%$ had severe disease (DAS-28 ESR $>5.1$ ). The mean DAS-28 and HAQ-DI scores at enrollment were $5.5 \pm 1.1$ and $1.4 \pm 0.6$ respectively, while mean disease duration was $6.7 \pm 6.2$ years with $53.2 \%$ of patients being seropositive (RF $(+): 49.2 \%$, Anti-CCP (+): $40.5 \%)$. A monthly administration was most preferred by patients ( $65.7 \%$ vs. $20.1 \%$ for twice per month, $11.8 \%$ for once per week and $3.9 \%$ for twice per week), and the large majority of patients $(75.2 \%)$ preferred the subcutaneous mode of administration. The mean compliance and 12-month persistence rates were $97.0 \%$ and $72.3 \%$ respectively. At 12 months, good EULAR response rate was achieved by $56.5 \%$ of patients and $40.8 \%$ were in DAS- 28 remission. Univariate analysis demonstrated that fulfillment of patient preferences was correlated to good EULAR response $(p<0.001)$, increased probability of being persistent $(\mathrm{p}=0.019)$ and satisfaction with treatment $(\mathrm{p}=0.063)$. Multivariate logistic regression analysis revealed that a good EULAR response was associated with satisfaction of patient preferences (OR 5.560, $p<0.001$ ), good patient knowledge of the disease (OR 1.327, $\mathrm{p}=0.006$ ), absence of history of comorbidities (OR 2.42, $p=0.014$ ) and lower SJC (OR 1.10, $p=0.021$ ), whereas anti-TNF persistence at 12 months was associated (Cox regression analysis) with seropositivity (HR $0.566, p=0.047)$ and a high baseline ESR $(>35 \mathrm{~mm} / \mathrm{h}(\mathrm{HR} 0.587, \mathrm{p}=0.071)$ ).

Conclusions: In anti-TNF treated RA patients, fulfillment of expressed treatment preferences was independently associated with a good EULAR response and correlated with drug persistence at 12 months, emphasizing the importance of patient preferences in treatment outcomes.

Acknowledgements: The study was funded by Merck Sharp \& Dhome S.A., Greece

Disclosure of Interest: None declared

DOI: 10.1136/annrheumdis-2017-eular.4920

\section{FRI0206 CORRELATION BETWEEN THE SERUM ETANERCEPT LEVEL AND RESPONSE TO ETANERCEPT TREATMENT IN PATIENTS WITH RHEUMATOID ARTHRITIS}

S.M. Zivojinovic ${ }^{1}$, M. Sefik-Bukilica ${ }^{2}$, N.S. Damjanov ${ }^{3} .{ }^{1}$ Clinical IV; ${ }^{2}$ Laboratory department ${ }^{3} \mathrm{Head}$ of Institute of rheumatology, Institute of Rheumatology, Belgrade, Serbia

Background: It is well documented that the blockade of TNF- $\alpha$ significantly reduces disease activity in patients with rheumatoid arthritis (RA). However, at least one third of patients receiving etanercept either do not respond to treatment, or lose initial responsiveness [1]. Recent findings indicate that lack of clinical response may be related with lowering the serum drug levels.

Objectives: To investigate the relationship between serum etanercept levels and response to etanercept treatment in patients with RA.

Methods: The study population consisted of fifty eight patients with rheumatoid arthritis (RA), all treated with etanercept. Disease activity was assessed according to the 28-joint count Disease Activity Score (DAS28) at baseline and 6 months of 
therapy. Clinical response was assessed using the European League Rheumatism (EULAR) response criteria [2]. Serum etanercept levels were measured by sandwich ELISA based on the ability of etanercept to bind TNF. Antibodies against etanercept were measured by bridging ELISA (Promonitor).

Results: The 47 female and 11 male were of a mean age $52.1 \pm 11.2$ years (22-87) and have been living with RA for a mean of $13.2 \pm 8.2$ years (2-24). At baseline the DAS28-eSR mean score was 6.1 11.0. After six months of etanercept treatment, $20(34.5 \%)$ patients were in remission, $20(34.5 \%)$ were in low disease activity and $18(31 \%)$ were in moderate disease activity. The serum etanercept levels were significantly higher in patients in remission compared with patients in moderate disease activity $(p=0.05)$. According to the EULAR response criteria, RA patients were divided into responders (52pts, $89.7 \%$ ) and non-responders (6 pts, 10.3\%). Median etanercept levels in all patients were $3.937 \mathrm{mcg} / \mathrm{ml}$. There were no statistical differences in etanercept levels between responders and non-responders patients $(\mathrm{p}=0.41)$. In addition, we stratified all patients into quartiles according to height of the etanercept level. The percentage of EULAR good responders was significantly different between the highest and the lowest quartiles $(\boldsymbol{p}<0.05)$.

Anti-etanercept antibodies were not found in any of the studied patients $(0 / 58)$.

Conclusions: Patients with RA who did not respond to etanercept treatment achieved lower etanercept levels compared with responding patients. Higher concentrations of the drug were associated with a better response to treatment. Further studies are needed to provide evidence for this approach.

\section{References:}

[1] Morand EF, Murphy K, Mackay F, Mariette X, Marcelli C. Antidrug antibodies (ADAb) to tumour necrosis factor (TNF)-specific neutralising agents in chronic inflammatory diseases: a real issue, a clinical perspective. Ann Rheum Dis. 2013 Feb;72(2):165-78.

[2] Van Gestel AM, Anderson JJ, van Riel PL, et al. ACR and EULAR improvement criteria have comparable validity in rheumatoid arthritis trials. American College of Rheumatology European League of Associations for Rheumatology.J Rheumatol 1999; 26:705-11.

Disclosure of Interest: None declared

DOI: 10.1136/annrheumdis-2017-eular.5957

\section{FRI0207 INDUCTION OF SUSTAINED REMISSION IN EARLY INFLAMMATORY ARTHRITIS WITH THE COMBINATION OF INFLIXIMAB PLUS METHOTREXATE, METHOTREXATE ALONE OR PLACEBO: THE DINORA TRIAL}

T.A. Stamm ${ }^{1}$, K. Machold ${ }^{2}$, D. Aletaha ${ }^{2}$, F. Alasti ${ }^{2}$, P. Lipsky ${ }^{3}$, D. Pisetsky ${ }^{4}$, R. Landewe ${ }^{5}$, D. van der Heijde ${ }^{5}$, A. Sepriano ${ }^{5}$, M. Aringer ${ }^{6}$, D. Boumpas ${ }^{7}$, G. Burmester ${ }^{8}$, M. Cutolo ${ }^{9}$, W. Ebener ${ }^{10}$, W. Graninger ${ }^{11}$, T. Huizinga ${ }^{5}$, G. Schett ${ }^{12}$, H. Schulze-Koops ${ }^{13}$, P.P. Tak ${ }^{14}$, F. Breedveld ${ }^{15}$, J. Smolen $^{16}$ ${ }^{1}$ Center for Medical Statistics, Informatics, and Intelligent Systems, Section for Outcomes Research, Medical University of Vienna, Vienna; ${ }^{2}$ Rheumatology, Medical University of Vienna, Wien, Austria; ${ }^{3}-,-$-, Charlottesville, Virginia; ${ }^{4}$ Duke University Medical Center, Durham, North Carolina, United States;

${ }^{5}$ Rheumatology, Leiden University Medical Centre, Leiden, Netherlands; ${ }^{6}$ Rheumatology, University Medical Center and Faculty of Medicine Carl Gustav Carus at the TU Dresden, Dresden, Germany; ${ }^{7}$ Rheumatology, University of Crete, Athens, Greece; ${ }^{8}$ Rheumatology, Charité, Berlin, Germany; ${ }^{9}$ Rheumatology, University of Genova, Genova, Italy; ${ }^{10}$ Rheumatology, Hietzing Hospital, Vienna; ${ }^{11}$ Rheumatology, Medical University Graz, Graz, Austria; ${ }^{12}$ Internal Medicine 3, Friedrich-Alexander University, Erlangen; ${ }^{13}$ Rheumatology, Ludwig Maximilians University of Munich, Munich, Germany; ${ }^{14}$ Rheumatology, University of Amsterdam, Amsterdam; ${ }^{15}$ Leiden University Medical Centre, Leiden, Netherlands; ${ }^{16}$ Rheumatology, Medical University of Vienna, Vienna, Austria

Background: Rheumatoid arthritis is a chronic form of inflammatory arthritis that is thought to have an early stage or reversibility with effective therapy ("window of opportunity").

Objectives: In the present study, we explored the effects of induction therapy with anti-TNF $\alpha$ antibody infliximab (IFX) plus methotrexate (MTX) compared with MTX alone and with placebo $(\mathrm{PL})$ in patients with very early inflammatory arthritis.

Methods: In an investigator-initiated, double-blind, randomized, placebocontrolled, multi-center trial, patients with synovitis of 12-16 weeks duration in at least 2 joints underwent one year of treatment with IFX in combination with MTX, MTX monotherapy or PL randomized in a 2:2:1 ratio. The primary endpoint was clinical remission after 1 year (sustained for at least two consecutive visits 8 weeks apart including week 54) with remission defined as no swollen joints, 0 - 2 tender joints and a C-reactive protein (CRP) level within the normal range $(<0.5$ $\mathrm{mg} / \mathrm{dl})$ or a normal ESR $(<25 \mathrm{~mm} / \mathrm{h})$. Further, sustainability of remission was assessed during the second year of the study, during which patients received no treatment. The trial was registered at www.isrctn.com (ISRCTN21272423).

Results: See Table 1

90 patients participated in the present study. At week 54 (primary endpoint), 32\% of the patients in the IFX+MTX group achieved sustained remission compared with $14 \%$ on MTX alone and $0 \%$ on PL (Table). This difference was statistically significant for all three groups $(\mathrm{p}<0.05)$ and for IFX+MTX vs PL $(\mathrm{p}<0.05)$ separately, but not for IFX+MTX vs MTX $(p=0.10)$, nor for MTX vs PL $(p=0.31)$. Remission was maintained during the second year on no therapy in $75 \%$ of the
Table 1. Number of patients in clinical remission at 6 months, one year and two years

\begin{tabular}{lccc}
\hline & $1:$ IFX+MTX (N=38) & $2:$ MTX (N=36) & $3:$ PL (N=16) \\
\hline 6 Mo & $10(26 \%)$ & $6(17 \%)$ & 0 \\
1 Year & $12(32 \%)$ & $5(14 \%)$ & 0 \\
2 Years $^{*}$ & $9(24 \%)$ & $1(3 \%)$ & $3(19 \%)$ \\
\hline${ }^{*} \mathrm{p}<0.05$ acros
\end{tabular}

${ }^{*} \mathrm{p}<0.05$ across the three groups.

IFX+MTX patients but was lost in $80 \%$ of the MTX-only-patients (Table). The analysis of radiographic progression did not reveal significant differences between the three treatment groups. The number needed to treat (NNT) to achieve one additional sustained remission at 52 weeks with IFX+MTX was 3 compared to placebo; the NNT for MTX alone versus placebo was 7 (NNT=6 for IFX+MTX vs MTX alone).

Conclusions: These results indicate that patients with early arthritis can benefit from induction therapy with anti-TNF plus MTX compared to MTX alone, suggesting the existence of a window of opportunity where intensive treatment can alter the disease evolution

Disclosure of Interest: T. Stamm Grant/research support from: For all authors: DINORA was partly funded by a grant from Janssen (previously Centocor). TS: AbbVie, Consultant for: AbbVie, Novartis, Speakers bureau: AbbVie, Janssen, MSD, Novartis and Roche, K. Machold: None declared, D. Aletaha Grant/research support from: AbbVie, Pfizer, Grünenthal, Merck Medac, UCB, Mitsubishi/Tanabe, Janssen and Roche, Consultant for: AbbVie, Pfizer, Grünenthal, Merck Medac, UCB, Mitsubishi/Tanabe, Janssen and Roche, F. Alasti: None declared, P. Lipsky Consultant for: Janssen, EMD Serono, Astra Zeneca, UCB, Roche, Celgene, Sanofi and Horizon, but none of them relates to the content of this manuscript, D. Pisetsky: None declared, R. Landewe Grant/research support from: Abbott, Amgen, Centocor, Novartis, Pfizer, Roche, Schering-Plough, UCB and Wyeth, Consultant for: Abbott/AbbVie, Ablynx, Amgen, Astra-Zeneca, Bristol Myers Squibb, Celgene, Janssen (formerly Centocor), Galapagos, Glaxo-Smith-Kline, Novartis, Novo-Nordisk, Merck, Pfizer, Roche, Schering-Plough, TiGenix, UCB and Wyeth, Employee of: RL is director of Rheumatology Consultancy BV which is a registered company under Dutch law., Speakers bureau: Abbott/AbbVie, Amgen, Bristol Myers Squibb, Janssen (formerly Centocor), Merck, Pfizer, Roche, Schering-Plough, UCB and Wyeth, D. van der Heijde Consultant for: AbbVie, Amgen, Astellas, AstraZeneca, BMS, Boeringer Ingelheim, Celgene, Daiichi, Eli-Lilly, Galapagos, Gilead, Janssen, Merck, Novartis, Pfizer, Regeneron, Roche, Sanofi and UCB, Employee of: $\mathrm{DH}$ is director of Imaging Rheumatology bv., A. Sepriano: None declared, M. Aringer Grant/research support from: MA's institution is clinical trial site for AbbVie, Astra Zeneca, Boehringer Ingelheim, Novartis, Pfizer and Roche., Consultant for: AbbVie, Astra Zeneca, BMS, Chugai, GSK, Hexal, Lilly, MSD, Novartis, Pfizer, Roche, Sanofi and UCB, Speakers bureau: AbbVie, Astra Zeneca, BMS, Chugai, GSK, Hexal, Lilly, MSD, Novartis, Pfizer, Roche, Sanofi and UCB, D. Boumpas: None declared, G. Burmester Grant/research support from: AbbVie, BMS, UCB and Roche, Speakers bureau: MSD, UCB and Roche, M. Cutolo Grant/research support from: BMS, Horizon, Actelion, Celgene and MSD, Speakers bureau: Biogen, Mundipharm, Pfizer and Menarini, W. Ebener Consultant for: Novartis and Abbvie, W. Graninger: None declared, T. Huizinga Consultant for: Merck, UCB, Bristol Myers Squibb, Biotest AG, Pfizer, GSK, Novartis, Roche, Sanofi-Aventis, Abbott, Crescendo Bioscience, Nycomed, Boeringher, Takeda, Epirus and Eli Lilly, G. Schett Speakers bureau: BMS, Celgene, Chugai, Lilly, Roche and UCB, H. Schulze-Koops Speakers bureau: AbbVie, Actelion, AstraZeneca, Biogen International, Boehringer Ingelheim, BMS, Celgene, Celltrion, Chugai, Cinfa Biotech, GSK, Hospira, Janssen-Cilag, Lilly, MSD, Medac, Merck, Mundipharma, Novartis, Pfizer, Hexal Sandoz, Roche and UCB, P. P. Tak Employee of: PPT has become an employee of GlaxoSmithKline. GSK has not been involved in this study., F. Breedveld: None declared, J. Smolen Grant/research support from: Abbvie, Lilly, MSD, Pfizer and Roche, Consultant for: Abbvie, Amgen, Astra-Zeneca, Astro, BMS, Boehringer-Ingelheim, Celgene, Celltrion, Chugai, Gilead, Glaxo, ILTOO, Janssen, Lilly, Medimmune, MSD, Novartis-Sandoz, Pfizer, Roche, Samsung, Sanofi and UCB

DOI: 10.1136/annrheumdis-2017-eular.3743

\section{FRI0208 COMPARISON OF EFFICACY, SAFETY AND PHARMACOKINETICS OF INFLIXIMAB BIOSIMILAR (BCD-055) AND INNOVATOR INFLIXIMAB}

L. Denisov ${ }^{1}$, I. Gordeev ${ }^{2}$, V. Mazurov ${ }^{3}$, A. Lila ${ }^{3}$, E. Zonova ${ }^{4}$, O. Nesmeyanova ${ }^{5}$, E. llivanova ${ }^{6}$, T. Plaksina ${ }^{7}$, A. Eremeeva ${ }^{8}$, A. Artemeva $^{8}$, E. Chernyaeva ${ }^{8}$, R. Ivanov ${ }^{8}$, S. Pimanov ${ }^{9}$, E. Kunder ${ }^{10}$, N. Soroka ${ }^{11} .{ }^{1}$ V.A. Nasonova Research Institute of Rheumatology; ${ }^{2}$ O.M. Filatov City Clinical Hospital No. 15, Moscow;

${ }^{3}$ I.I. Mechnikov North-Western State Medical University, Saint-Petersburg; ${ }^{4}$ Novosibirsk State Medical University, Novosibirsk; ${ }^{5}$ Chelyabinsk Regional Clinical Hospital, Chelyabinsk; ${ }^{6}$ Leningrad Regional Clinical Hospital,

Saint-Petersburg; ${ }^{7}$ N.A. Semashko Nizhny Novgorod Regional Clinical Hospital, Nizhny Novgorod; 8 Jcs Biocad, Saint-Petersburg, Russian Federation; ${ }^{9}$ Vitebsk Regional Clinical Hospital, Vitebsk; ${ }^{10} 1$ st City Clinical Hospital; ${ }^{11}$ 9th City Clinical Hospital, Minsk, Belarus

Background: Infliximab (IFX) was one of the first genetically engineered biologics successfully applied for medical use in patients with active RA and patients with AS. Previous preclinical studies showed that BCD-055 is highly similar to innovator IFX. 